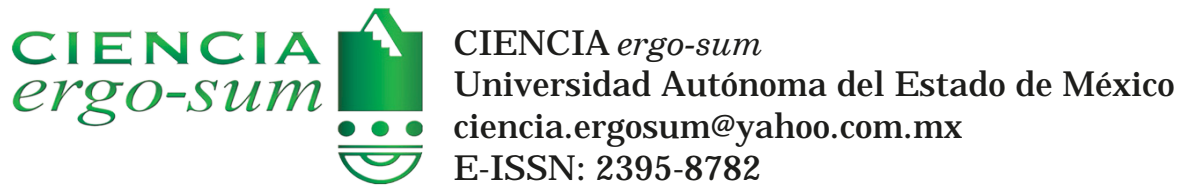

\title{
Los retos actuales en la ingeniería de proteínas
}

J iménez Rosales, Angélica

Los retos actuales en la ingeniería de proteínas

CIENCIA ergo-sum, vol. 26, núm. 3, noviembre 2019-febrero 2020|e66

Universidad Autónoma del Estado de México, México

Esta obra está bajo una Licencia Creative Commons Atribución-NoComercial-SinDerivar 4.0 Internacional.

J iménez Rosales, A. (2019). Los retos actuales en la ingeniería de proteínas. CIE NCIA ergo-sum, 26(3). https://doi.org/10.30878/ces.v26n3a9 


\section{Los retos actuales en la ingeniería de proteínas}

Current challenges in protein engineering

Angélica Jiménez Rosales

Universidad Autónoma del Estado de México, México

ajimenez.qfb@gmail.com

Recepción: 17 de julio de 2018

Aprobación: 30 de octubre de 2018

\section{RESUMEN}

Las proteínas son la maquinaria molecular que sustenta la vida, y el ser humano ha buscado adaptarlas para resolver sus necesidades. En esta revisión, se presentan los fundamentos sobre las proteínas, sus niveles estructurales, plegamiento, las enzimas y su actividad catalítica y las limitantes de sus aplicaciones debido a su naturaleza. De manera simplificada, se ilustran las bases conceptuales y metodológicas de la ingeniería de proteínas, su alcance y las perspectivas de su aplicación en la ciencia y la innovación de procesos. Se concluye que la ingeniería de proteínas es una rama que continúa implementando herramientas computacionales e ingeniería genética-proteómica por medio de la cual es posible la generación de nuevas proteínas para ampliar sus aplicaciones en diversos procesos.

PALABRAS CLAVE: enzimas, ingeniería de proteínas, diseño racional, evolución dirigida.

\section{Abstract}

Proteins are the molecular tools of life and human being have sought ways to adapt them to meet their needs. The aim of this text is to present the scientific grounds about proteins such as their structural levels, folding, catalytic activity of enzymes, and limitations of their applications due to their nature. The conceptual and methodological bases of protein engineering are illustrated, in a simplified manner, including the scope and future perspectives towards the advance of science and innovation of processes. It is concluded that protein engineering is a field which continues to implement computational and genetic-proteomic engineering tools, through which new proteins can be generated to expand their applications in different processes.

KEYWORDS: enzymes, protein engineering, rational design, directed evolution.

\section{INTRODUCCIÓN}

Las proteínas son biomoléculas formadas por cadenas de aminoácidos que desempeñan funciones cruciales en los seres vivos. Estas moléculas muestran secuencias y estructuras diversas y complejas que les confieren diferentes propiedades fisicoquímicas, además de una actividad biológica específica, la cual puede ser meramente estructural, de transporte, de señalización, para movimiento o de catálisis, como es el caso de las enzimas.

La ingeniería de proteínas surge de la necesidad del ser humano de modificar la actividad catalítica de diferentes enzimas o propiedades de proteínas ya existentes en la naturaleza para aprovecharlas hacia el mejoramiento de procesos industriales, generación de productos comerciales con valor añadido, diseño de biomateriales y la innovación de nuevas tecnologías. Para ello, se ha tenido que analizar y comprender la estructura, la estabilidad y el plegamiento de estas macromoléculas, las interacciones en la estabilización conformacional de las cadenas polipeptídicas, los factores del ambiente molecular y celular que coadyuvan su función o actividad catalítica (Amara, 2013).

Con ayuda de herramientas de la biología molecular y modelaje computacional, la ingeniería de proteínas ha logrado múltiples aplicaciones y eventualmente podrá constituir la base de una bioeconomía y nuevas tecnologías sustentables (Lokko et al., 2018). 


\section{INTERÉS BIOTECNOLÓGICO DE LAS ENZIMAS}

El uso de microorganismos para la producción de diversos productos se ha llevado a cabo desde la antigüedad, por ejemplo, en la elaboración del pan, vino y principalmente en productos lácteos fermentados como el yogurt y el queso. Aun hasta inicios del siglo XX no se sabía que la transformación de los alimentos podía ocurrir en ausencia de microorganismos, pero gracias a los estudios de Eduard Buchner se comprendió que detrás de los procesos celulares había biomoléculas encargadas de llevar a cabo las reacciones bioquímicas, a las cuales se les llamó enzimas. El trabajo de Buchner fue tan sustancial para la comprensión de la bioquímica actual que lo hizo merecedor del premio Nobel en Química en 1907 (Eduard Buchner-Facts, 2018), y gracias a él se tuvo una mejor comprensión de los procesos celulares. Actualmente, se han aislado y caracterizado diversas enzimas de microorganismos como virus, bacterias y hongos con infinidad de funciones que se han adaptado para su aplicación industrial y en productos de consumo (Afroz et al., 2015).

Algunos de los ejemplos de las múltiples aplicaciones de las enzimas se dan tanto en la producción de antibióticos como también en productos alimenticios, detergentes o aditivos. La investigación y el desarrollo tecnológico en áreas como la biología molecular, biomedicina, biotecnología y genética serían imposibles sin la utilización de enzimas u otras proteínas (Singh et al., 2016), las cuales traen como ventajas implementar procesos amigables con el ambiente, además de un alto rendimiento de producto y su producción estereoselectiva.

\section{IMPORTANCIA DE LAS ENZIMAS EN LAS REACCIONES QUÍMICAS}

Muchas reacciones químicas involucran la creación y rompimiento de nuevos enlaces químicos. Para esto, la molécula debe de llegar a un estado de transición, una condición altamente inestable que permite la formación de una estructura intermediaria con un nivel energético mayor al de los reactivos. Al terminar la reacción se llega a los productos con nivel de energía más bajo y estable.

La energía requerida para llegar al estado intermediario es la energía de activación $\left(\Delta \mathrm{G}^{\ddagger}\right)$, la cual es cubierta por la absorción de energía del entorno por parte de las moléculas incrementando sus vibraciones, rotaciones y colisiones. Sin embargo, en muchas ocasiones, las reacciones tienen una barrera de activación muy grande que ralentiza que ocurra o incluso que no proceda en determinadas condiciones, pues la molécula intermediaria puede desestabilizarse y dar origen a otro producto. Además, las colisiones entre moléculas son efectivas solamente para llegar al intermediario cuando su orientación es la adecuada (Peterson et al., 2007).

La función de los catalizadores químicos y biológicos es disminuir la energía de activación y aumentar su velocidad de reacción (gráfica 1). Las enzimas son los catalizadores biológicos por excelencia con alta afinidad de unión específica hacia un sustrato que es inducido al estado de transición, lo estabilizan mediante interacciones entre sus grupos funcionales y además lo orientan para la generación de un producto específico. Las enzimas catalizan una infinidad de reacciones químicas bajo diferentes condiciones en un orden de 1015-1023 veces, y sin ellas los procesos bioquímicos tardarían tanto que la vida no alcanzaría (Ramírez et al., 2016).

La actividad catalítica de las enzimas ha atraído el interés del hombre para aplicarlas en diferentes procesos fuera del ambiente celular. Al respecto, a diferencia de los catalizadores inorgánicos, las enzimas son casi exclusivamente proteínas y son biodegradables, tienen alta especificidad hacia su sustrato y producto, hay ausencia de reacciones colaterales y también limitada generación de residuos. Además, un medio acuoso y condiciones moderadas de temperatura y presión son suficientes para su actividad, por lo que su uso es seguro y amigable con el ambiente; tecnológicamente son eficientes por su alta actividad y un bajo costo de energía en el proceso (Patel et al., 2017). Muchas enzimas de aplicación biotecnológica pertenecen a bacterias, hongos y plantas de la naturaleza. 


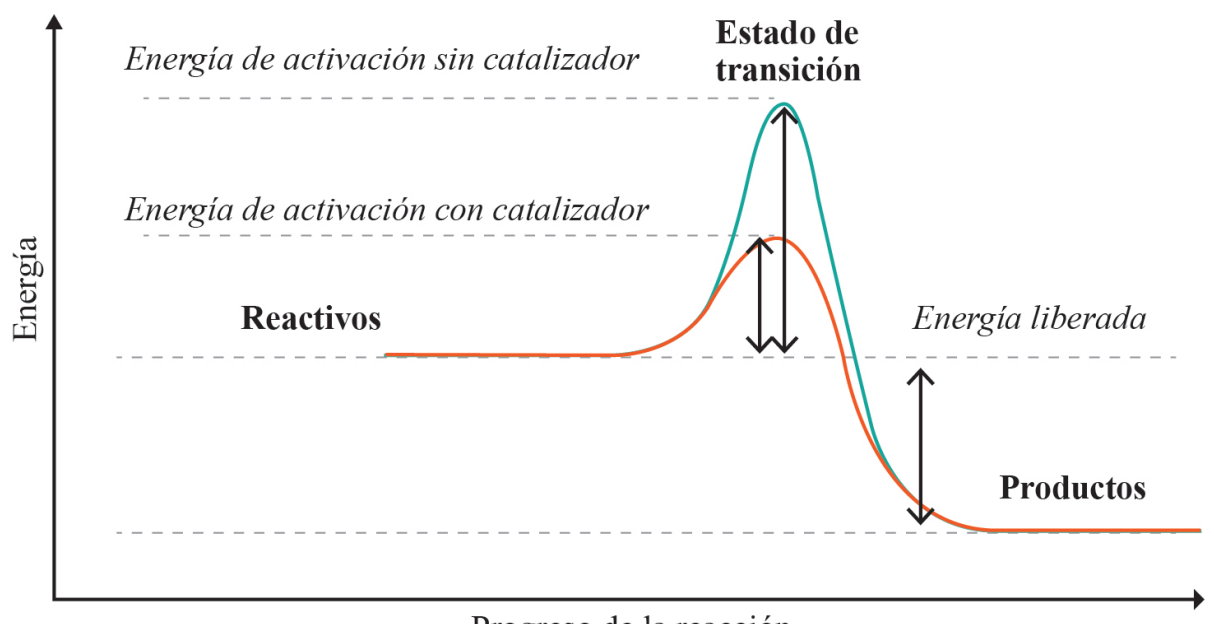

Progreso de la reacción

GRÁFICA 1

Diagrama de la energía de activación

Fuente: adaptado de Cooper, 2000.

Nota: corresponde a la energía requerida para que la reacción ocurra. Los catalizadores bajan la energía de activación y aceleran la reacción.

No obstante, las enzimas provenientes de la naturaleza (o nativas) han sido generadas y seleccionadas por los procesos evolutivos de un hábitat específico para actuar bajo ciertas condiciones bioquímicas; por ejemplo, puede ser que su actividad se limite a un rango de temperaturas, de concentraciones de sustrato o $\mathrm{pH}$, que se oxiden fácilmente, que la selectividad de sustrato no sea la deseada o que el rendimiento sea bajo ocasionando que las enzimas tengan limitaciones en su aplicación biotecnológica. La adaptación de microorganismos para que realicen estos procesos no vuelve el panorama más sencillo, pues se requiere de nutrientes más complejos y condiciones específicas para su crecimiento, además de que la purificación del producto final es un proceso difícil (Rigoldi et al., 2018).

\section{LA MODIFICACIÓN DE PROTEÍNAS Y SUS ENFOQUES ESTRATÉGICOS}

Tomando como base la problemática de que las enzimas nativas no actúan bajo condiciones diferentes a sus condiciones estándar, se ha buscado rediseñar enzimas; sin embargo, es complicado debido a su estructura compleja y subunidades con diferentes dominios, funciones e interacciones con las demás subunidades, incluso, ocurren en ellas cambios estructurales en el reconocimiento de su sustrato y en la catálisis (Yu et al., 2016; Jimenez-Rosales y Flores-Merino, 2008). Por estas características, no es fácil diseñar artificialmente una enzima basándose únicamente en su secuencia, pues su funcionalidad depende de su estructura tridimensional, que es uno de los obstáculos mayores en la ingeniería de proteínas. Los avances en el área en su mayoría han permitido diseñar fusiones de proteínas enteras o de sus dominios (Milczek, 2018), pero lograr rediseñar una estructura o una nueva actividad o propiedades de una proteína con el resultado deseado es un reto mayor. Una reflexión sobre la problemática es que ha transcurrido más de medio siglo desde que se reportaron las dos primeras estructuras tridimensionales de proteínas (la mioglobina y la hemoglobina) a las cuales han seguido decenas de miles proteínas distintas, pero la predicción del plegamiento y la actividad enzimática siguen siendo problemas no resueltos. No obstante, existen avances importantes y se pueden resumir en dos enfoques: el racional y la evolución dirigida, los cuales son diferentes entre sí, pero no son mutuamente excluyentes.

a) Enfoque racional: se basa en hacer modificaciones calculadas para cambiar la estructura y estudiar el efecto de una mutación o para obtener una nueva actividad/propiedad de la proteína. Demanda mucha información 
sobre la estructura de la enzima de interés y su mecanismo de catálisis para determinar los componentes catalíticos y sus interacciones durante la reacción, además otros detalles como las distancias, enlaces y los posibles cambios conformacionales que permitan obtener la función deseada (Tiwari, 2016).

Es muy común que para realizar la mutación sitio-dirigida en la proteína de interés se usen primers mutagénicos que incluyan en su secuencia un codón modificado que sustituye el codón del aminoácido de interés. Los primers se utilizan en una reacción similar a una PCR que permite la replicación del gen de la proteína de interés con la mutación específica. Después, el DNA mutado se liga a un vector, que es un fragmento de DNA natural o sintético que funciona como vehículo para transferir genes a una célula. Así, el DNA mutado se expresa a una proteína que se purifica para su evaluación (Carter y Shieh, 2015). Lamentablemente, las mutaciones afectan la estructura y estabilidad de cualquier enzima y pueden perder su actividad. Por ello, para este enfoque, la estructura de la molécula es clave. Técnicas como las que se presentan a continuación pueden determinarla:

- Resonancia magnética nuclear: brinda información acerca de la estructura y de los cambios dinámicos en la molécula por la detección de modificaciones en la frecuencia de resonancia de los núcleos atómicos magnéticamente activos cuando se encuentran sometidos a un campo magnético externo; no obstante, por su complejidad se encuentra limitada a proteínas de bajo peso molecular (<30 kD) (Chatham y Blackband, 2001).

- Cristalografía de rayos X: consiste en la difracción de un haz de fotones en un material cristalino como resultado de la interacción con los electrones de los planos cristalográficos; el análisis del patrón de difracción de los rayos emergentes puede generar un mapa de densidad electrónica que después de un refinamiento origina el modelo atómico de una molécula. Una desventaja es que la cristalización de proteínas en solución es un proceso físico lento de evaporación del líquido, lo cual implica cambios constantes en la concentración de moléculas y iones que resultan en el cambio de orientación de ciertas regiones de la estructura proteica distorsionando su ordenamiento geométrico y repetitividad en el espacio; esto ocasionaría que algunas veces la identidad y posiciones de los átomos sólo puedan ser deducidas a partir de los átomos a su alrededor (Shi, 2014).

- Criomicroscopía electrónica: al someter una solución acuosa a un enfriamiento rápido y a muy bajas temperaturas, las moléculas que contiene la solución quedan congeladas en la misma posición en la que estaban (a diferencia de un congelamiento lento en el que las moléculas forman una estructura ordenada); esta muestra vitrificada puede someterse a un análisis por un haz de electrones de un orden de unas milésimas de nanómetro que permite detectar los detalles estructurales a nivel atómico. De esta manera, si la muestra vitrificada contiene biomoléculas como proteínas, la técnica permite deducir su estructura con la ventaja de observarla en la conformación que presenta en el organismo vivo. Además, permite el estudio de complejos macromoleculares de gran tamaño y en bajas cantidades; aun así, entre sus limitaciones está el que tiene una relación de señal/ruido muy baja y su resolución, o el detalle a nivel atómico que puede obtenerse, depende de las condiciones instrumentales por lo que varía de $3 \AA$ a $~ 3 \mathrm{~nm}$ (Carroni y Saibil, 2016; Wangy Wang, 2016).

Hasta el momento, la cristalografía en rayos $\mathrm{X}$ ha dominado el área y gracias a sus diversas aplicaciones ha sido la técnica que directa o indirectamente ha resultado en la mayor cantidad de ganadores al premio Nobel a lo largo de la historia (29 laureados), pero la criomicroscopía electrónica está adquiriendo popularidad y gracias a ella se han resuelto muchas nuevas estructuras, por ejemplo las proteínas de la cápside del virus Zika. El Premio Nobel de Química de 2017 se asignó a Jacques Dubochet, Joachim Frank y Richard Henderson, quienes ayudaron a desarrollar dicha técnica (Cressey y Callaway, 2017). No obstante, aunque la cantidad de proteínas que existen en la naturaleza son "cientos de millones", a la fecha únicamente una mínima fracción de un aproximado de 140000 estructuras (RCSB PDB 2018) se ha obtenido de manera experimental. Además, no es fácil purificar y cristalizar uniformemente muchas proteínas para su estudio. Lo anterior ha propiciado el desarrollo del modelaje molecular computacional (Hospital et al., 2015). 
En 2013 se concedió el Premio Nobel a Martin Karplus, Michael Levitt y Arieh Warshel por su aporte a la simulación in silico de la mecánica y dinámica de sistemas complejos macromoleculares como las proteínas (The Nobel Prize in Chemistry 2013, 2018). En la actualidad los algoritmos computacionales son una de las herramientas más importantes en la predicción de estructuras. Aunque no son exactos, mucho se ha avanzado en ellos y es posible utilizar más de uno para complementar el modelaje, pues cada algoritmo funciona bajo diferentes postulados. Una clasificación general los agruparía en a) métodos ab initio que basados en los principios físicoquímicos buscan identificar el plegamiento de mínima energía. b) Los métodos comparativos que buscan las semejanzas y regularidades entre las proteínas para seleccionar una estructura conocida y predecir el plegamiento por comparación. c) Los métodos empíricos emplean estrategias heurísticas para encontrar un plegamiento con múltiples opciones que hacen imposible una exploración exhaustiva. Por último, el modelo debe apegarse a las leyes de la química y la física y representar la realidad del plegamiento biológicamente relevante. Así, la evaluación del resultado es esencial, aunque esto es lo más difícil de evaluar y lo que genera mayor incertidumbre (Wójcikowski et al., 2017).

Sin embargo, aun con el uso de estas herramientas, usualmente las mutaciones no tienen el efecto esperado y hacen que el proceso de modificación hacia una molécula eficiente sea largo y tedioso. Quizá la mayor desventaja del enfoque racional es que el análisis se hace bajo una estructura aislada y estática y que no está en el cambio dinámico de las condiciones nativas, pues en condiciones naturales las proteínas son flexibles y se moldean, doblan o cambian de conformación al unirse a otras moléculas. También, existen reportes de proteínas que describen parte de estructuras como proteínas intrínsecamente desestructuradas (IDP por sus siglas en inglés) y no tienen una estructura definida. Son muchas las proteínas que entran en este concepto y cuyas estructuras no pueden ser definidas por los métodos existentes, pues sus dominios desestructurados son de libre interacción y por ello resulta difícil cristalizarlas (Ahrens et al., 2017; Kjaergaard y Kragelund, 2017).

b) Evolución dirigida: la evolución es un proceso constante cuyos efectos se observan de manera evidente, por ejemplo la resistencia de bacterias a ciertos antibióticos o insectos a plaguicidas, y otros casos extraordinarios en los que bacterias, hongos y plantas han desarrollado mecanismos bioquímicos para degradar moléculas tóxicas y contaminantes que hasta hace unos pocos años no eran biodegradables (Pellis et al., 2016; Urbanek et al., 2017).

La evolución dirigida se fundamenta en los principios del proceso evolutivo darwiniano que ocurre en la naturaleza y por el cual ocurre la especiación en las condiciones específicas del ambiente; está en función de la variación y la selección, pero también del azar. La especiación es un proceso imprevisto que está influenciado por una secuencia de eventos, unos externos y otros propios de la célula sucediendo que ambos se influencian mutuamente. Las presiones selectivas existentes determinan cuáles individuos sobreviven, lo que puede hacer que las poblaciones se distancien genéticamente. Cuando un grupo de organismos queda impedido por el tiempo suficiente para combinar su acervo genético con las otras poblaciones de la especie, en algún punto en el tiempo éstas se volverán diferentes genéticamente, es decir, la especiación habrá iniciado (Safran y Nosil, 2012).

En el caso de las enzimas, este proceso se imita para la generación aleatoria de variedad genética y la selección por actividad específica. El proceso se realiza bajo condiciones controladas y a microescala dentro del laboratorio produciendo mutaciones generalizadas en todo el gen de la enzima en bacterias transformadas que posteriormente expresan las variaciones del gen con las condiciones requeridas y a través de la selección experimental se obtienen las mejores variantes. Esto se hace de manera secuencial y en repetidas ocasiones con la finalidad de afinar la actividad enzimática deseada (Packer y Liu, 2015).

Existen muchas metodologías para introducir mutaciones al ADN que pueden aplicar principios de la recombinación de genes homólogos y pueden involucrar la mezcla, deleción o adición de secuencias de nucleótidos o la mutagénesis aleatoria de nucleótidos en el gen. Así, las mutaciones al azar confieren cambios a la estructura y por tanto a la actividad enzimática. Después el gen mutado se introduce en un vector para insertarlo en microorganismos para su expresión genética como proteína, seguido de la cuidadosa selección de mutantes con fenotipos deseables y su posterior purificación. 
La actividad catalítica de interés se evalúa en las diferentes proteínas: se seleccionan las mejores variedades y se someten de nuevo a ciclos repetidos de mutagénesis y selección hasta obtener la variedad enzimática que presenta una considerable eficiencia de catálisis (Yang et al., 2017). De esta manera, es posible acelerar un proceso de evolución molecular que en la naturaleza toma "millones de años" a unas cuantas semanas.

Es importante mencionar que desde la antigüedad el ser humano ha realizado este proceso de manera similar (aunque sin saberloy sin algún laboratorio) a través de la selección preferencial y de la cruza de ejemplares predilectos para lograr las variaciones deseadas. Tal ejemplo se observa en los perros de "raza pura" y también en los cultivos domesticados por el ser humano como maíz, papa y trigo. Sin embargo, fue en años recientes cuando se concibió la idea de llevar este proceso al laboratorio para la ingeniería de proteínas y su aplicación biotecnológica. Actualmente, los avances y las aplicaciones de esta técnica han sido sustanciales en la biotecnología actual tanto que en 2016, 2017 y 2018, Frances Arnold, pionera en esta técnica, recibió el Premio de Tecnología del Milenio (del inglés Millennium Technology Prize) (Manas, 2016), el premio Raymond y Beverly Sackler en Investigación de Convergencia (del inglés Raymond and Beverly Sackler Prize in Convergence Research) (NAS, 2017) y el premio Nobel en Química (The Nobel Prize in Chemistry 2018, 2018).

La principal ventaja de la evolución dirigida es que no requiere conocer la estructura de la proteína para generar en ella una nueva actividad. Sin embargo, debido a la generación de cientos o miles de variaciones mutantes durante el proceso, se requiere de un cuidadoso método de selección y de métodos eficientes, automatizados y baratos para la evaluación de las variantes (Bunzel et al., 2018).

Para una comprensión más a fondo de estos métodos se sugiere revisar Directed evolution library creation: Methods and protocols editado por Arnold y Georgiou (2003) y los capítulos dos y tres de Protein engineering techniques: Gateways to synthetic protein universe de Poluri y Gulati (2017).

\section{Un PAR DE EJEMPLOS DE LA INGENIERÍA DE PROTEÍNAS}

Con la finalidad de resaltar el potencial de impacto de la ingeniería de proteínas, se describe el caso a través del enfoque racional de la modificación de la proteína verde fluorescente (GFP por sus siglas en inglés) realizada por Roger Tsien dándole el mérito para su condecoración con el Nobel en 2008 (Roger Y. Tsien-Facts, 2018). Esta modificación consistió en la modificación estructural del cromóforo fluorescente de citrina, contenido en la GFP, y conformado naturalmente por la ciclación de serina65 (Ser-65), tirosina66 (Tyr-66) y glicina67 (Gly67) mediante la sustitución del residuo Tyr-66 por otros aminoácidos aromáticos (figura 1). El nuevo cromóforo tiene diferente conformación y número de enlaces con electrones deslocalizados generando diferentes colores de emisión como cian, violeta, azul y amarillo para los aminoácidos triptófano, fenilalanina, histidina, o la sustitución de Serina203 (Ser-203, estructuralmente próximo de Tyr-66) por Tyr respectivamente (Tsien, 1998).

De esta manera, la GFP y sus variantes de diferentes colores de fluorescencia son utilizadas como proteína de fusión para estudiar otras proteínas y tejidos celulares. También, se han generado otras mutaciones complementarias que propician la ionización del cromóforo, la expresión y plegamiento de la proteína a diferentes temperaturas o pH, un mayor coeficiente de extinción, entre otras (Aliye et al., 2015; Hutter, 2012; Rosenman et al., 2014).

Otro caso de interés para el lector, pero ahora enfocado en la vía de la evolución dirigida, es la ruta de síntesis de la sitagliptina, un fármaco para el tratamiento de la diabetes tipo 2 (Thomson y Vallon, 2018). Antes de 2006, su síntesis consistía en nueve pasos con diferentes reacciones, solventes y reactivos, prolongado tiempo de reacción y purificación, y una falta de pureza enantiomérica (Mallela et al., 2013). Por fortuna, en 2006 se implementó un nuevo proceso de síntesis química de tres pasos que redujo tiempo y procesos de purificación. Posteriormente, y de mayor interés para este artículo, en 2010 el proceso otra vez fue innovado a una síntesis química-biotecnológica mediante la evolución de una enzima transaminasa, a la cual se le desarrolló la actividad catalítica para la hidrogenación asimétrica de una enamina (figura 2). El gen de dicha enzima fue mutado aleatoriamente siguiendo una cuidadosa selección en cada ciclo de acuerdo con las condiciones de interés. El proceso de variación-selección se realizó por once ciclos hasta obtener una proteína (con 27 mutaciones) de una actividad de más de 80 \% y 99\% de enantioselectividad (Valavanidis, 2017). 


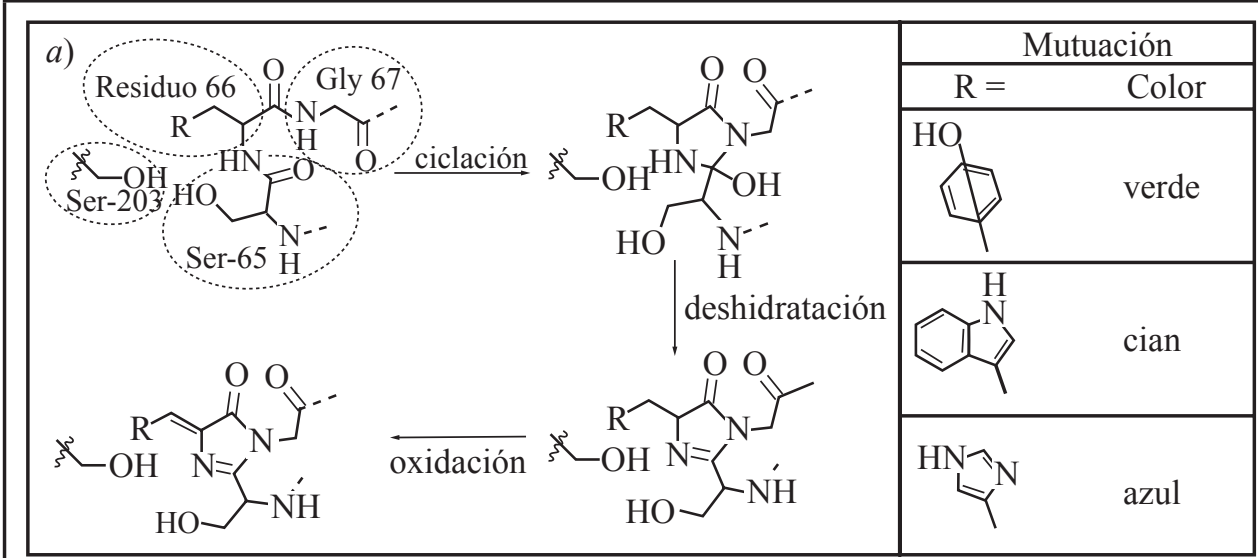
b)

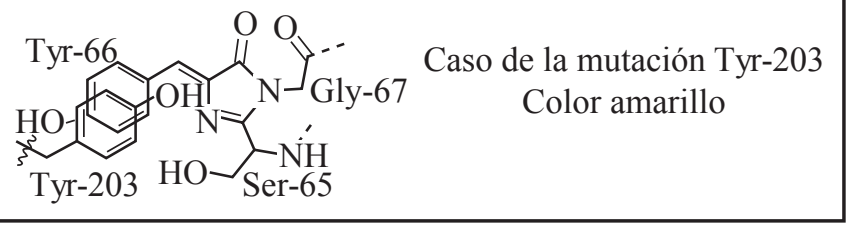

FIGURA 1

Reacción de los aminoácidos para formar el cromóforo de citrina

Fuente: adaptado de Tsien, 1998.

Nota: a) Diagrama con el mecanismo de formación del cromóforo de citrina y las variantes resultantes con las mutaciones correspondientes en el residuo 66. b) Diagrama del cromóforo de citrina resultante con la mutación del residuo 203 a Tyr.

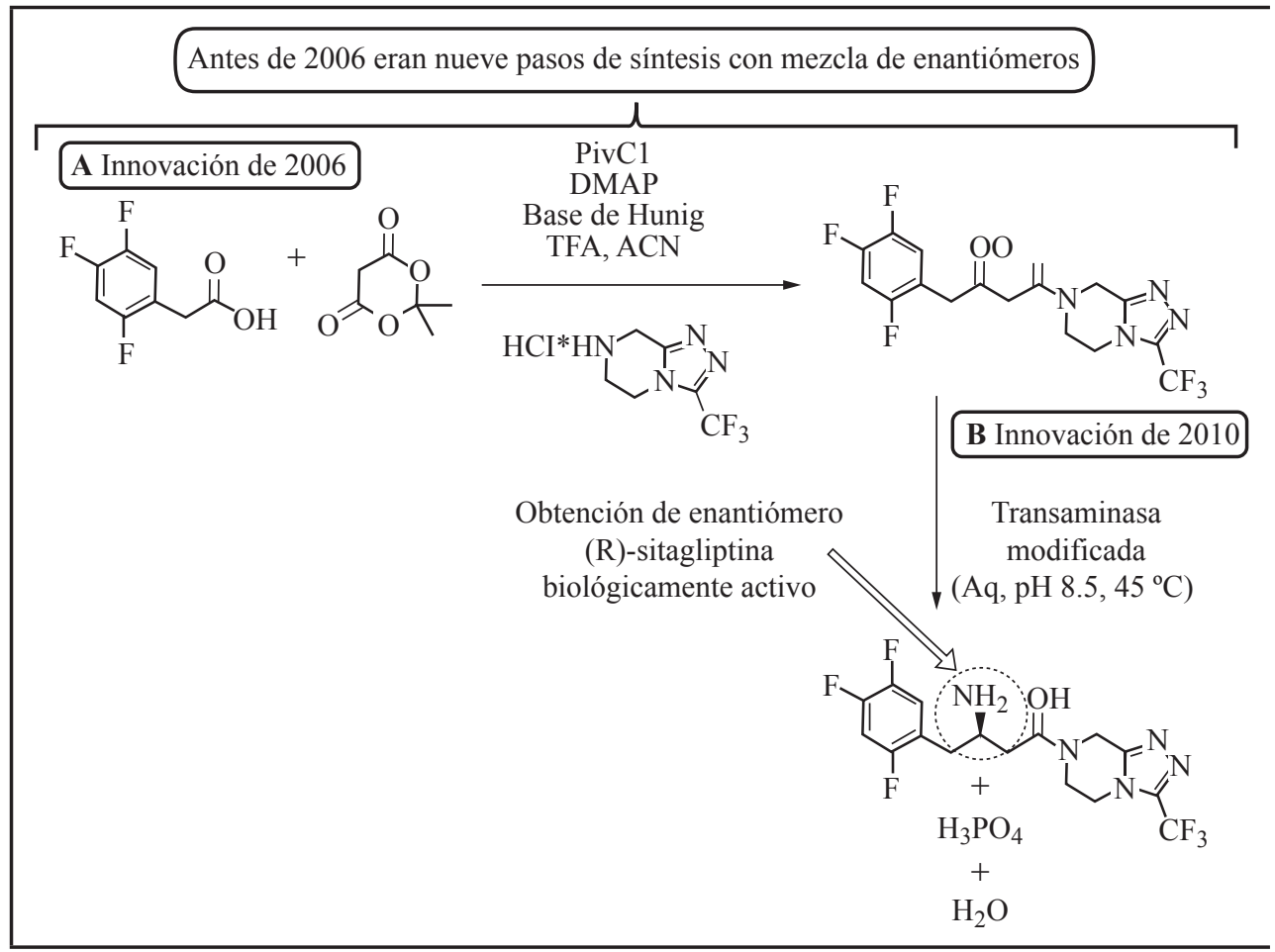

FIGURA 2

Diagrama de la nueva ruta de síntesis de la sitagliptina

Fuente: adaptado de Valavanidis, 2017.

Nota: se muestra la innovación en 2006 en la síntesis química por la ruta A y la innovación de 2010 en la ruta B con la evolución dirigida de una transaminasa para obtener el producto activo. 
Ambas rutas se complementan y fueron ganadoras del Premio Presidencial de Química Verde (del inglés Presidential Green Chemistry Award) en los Estados Unidos en 2006 y 2010 (US EPA, 2013a; US EPA, 2013b). Este proceso sigue siendo hasta ahora uno de los logros más importantes en la historia de la ingeniería y aplicación de proteínas (Guan et al., 2015).

\section{Conclusiones}

Los procesos enzimáticos son útiles en la industria, en la investigación e incluso en los productos de uso diario en nuestra vida debido a que las enzimas son catalizadores naturales selectivos y muy eficientes, además de que son amigables con el medioambiente. La estructura de las proteínas es única y determina la función catalítica deseada; lamentablemente, dado que las condiciones fisicoquímicas de reacción alteran dicha estructura, y por tanto su actividad, las enzimas naturales tienen una limitada aplicación en diversos procesos.

Se ha buscado modificar a las enzimas a través de dos enfoques no excluyentes: $a$ ) el racional y $b$ ) la evolución dirigida. El racional busca realizar mutaciones sistemáticas a partir de una estructura conocida y un mecanismo de catálisis propuesto; por ello, su principal limitante es la determinación de la estructura proteica. Por su parte, la evolución dirigida se enfoca en crear aleatoriamente una variedad de mutaciones en un gen para después hacer una selección de la proteína con base en las condiciones de interés; de ahí que su principal limitante sea la aplicación de un método analítico que permita procesar miles de muestras para su selección y que además sea rápido y económico.

La adecuada aplicación de estos enfoques ha permitido tanto la generación de nuevas proteínas como también adentrarse en su secuencia, estructura y mecanismos de catálisis para modificar la estructura nativa y crear una nueva actividad. Son numerosos los ejemplos reportados en la literatura en los que elegantemente se han modificado enzimas para solucionar diversos problemas. Por el momento, hay enormes retos, pero sin duda, dentro de algunos años, habrá un uso diversificado de estas biomoléculas versátiles.

\section{Análisis prospectivo}

Mediante los avances en la ciencia y tecnología, el ser humano podrá combinar y rediseñar proteínas capaces de catalizar reacciones no existentes en la naturaleza que tendrán infinidad de aplicaciones. Por mencionar algunas, habría que considerar la obtención de nuevos materiales y fármacos, la optimización de procesos, el mejoramiento de terapias en la medicina, la innovación en la generación de energía, el propiciar una interacción sustentable del hombre con su medioambiente, la producción de materiales bioinspirados y motores moleculares para fines tecnológicos, así como el diseño de nanoestructuras de biomateriales en nanomedicina y biotecnología.

Es de esperarse que la demanda del diseño de enzimas siga en aumento y que sus aplicaciones continúen expandiéndose. Con ello, para facilitar el diseño, la modificación y la producción de enzimas deberán desarrollarse algoritmos computacionales más completos y fabricar computadoras con mayor capacidad de procesamiento, nuevas metodologías para mutagénesis en sitios clave y formas efectivas de evaluación de actividad; también se incluye el desarrollo e implementación de nuevos sistemas de producción de proteínas artificiales que no dependan del cultivo y propagación de células. Para lograr estas metas, el trabajo por realizar en el área es muy demandante, pues requiere de una colaboración mundial y de la aplicación de tecnología de punta. Sin embargo, el futuro de esta área se vislumbra muy emocionante y prometedor.

La naturaleza genera innovación y mediante la ciencia tenemos la oportunidad de explorarla para mejorar el mundo en el que vivimos. Por ello, es importante ver las maravillas que nos presenta y tomar inspiración de los modelos biológicos para diseñar nuevos procesos industriales, tratamientos médicos o materiales con nuevas propiedades, y para lograrlo es clave primordial la ingeniería de proteínas en este paso. 


\section{Agradecimientos}

Gracias al apoyo del convenio PRODEP 511-6/17-9932 proyecto 993291.

\section{REFERENCIAS}

Afroz, Q. M., Khan, K. A., Ahmed, P., \& S., U. (2015). Enzymes used in dairy industries. International Journal of Applied Research, 1(10), 523-527.

Ahrens, J. B., Nunez-Castilla, J., \& Siltberg-Liberles, J. (2017). Evolution of intrinsic disorder in eukaryotic proteins. Cellular and Molecular Life Sciences, 74(17), 3163-3174. https://doi.org/10.1007/s00018-017-2559-0

Aliye, N., Fabbretti, A., Lupidi, G., Tsekoa, T., \& Spurio, R. (2015). Engineering color variants of green fluorescent protein (GFP) for thermostability, $\mathrm{pH}$-sensitivity, and improved folding kinetics. Applied Microbiology and Biotechnology, 99(3), 1205-1216. https://doi.org/10.1007/s00253-014-5975-1

Amara, A. A. A. F. (2013). Pharmaceutical and industrial protein engineering: where we are? Pakistan Journal of Pharmaceutical Sciences, 26(1), 217-232.

Arnold, F. H., \& Georgiou, G. (Eds.). (2003). Directed Evolution Library Creation: Methods and Protocols. Humana Press. Retrieved from https://www.springer.com/gp/book/9781588292858

Bunzel, H. A., Garrabou, X., Pott, M., \& Hilvert, D. (2018). Speeding up enzyme discovery and engineering with ultrahigh-throughput methods. Current Opinion in Structural Biology, 48, 149-156. https://doi. org/10.1016/j.sbi.2017.12.010

Carroni, M., \& Saibil, H. R. (2016). Cryo electron microscopy to determine the structure of macromolecular complexes. Methods, 95, 78-85. https://doi.org/10.1016/j.ymeth.2015.11.023

Carter, M., \& Shieh, J. (2015). Chapter 10-Molecular Cloning and Recombinant DNA Technology. In M. Carter \& J. Shieh (Eds.), Guide to Research Techniques in Neuroscience (2nd ed., pp. 219-237). San Diego: Academic Press. https://doi.org/10.1016/B978-0-12-800511-8.00010-1

Chatham, J. C., \& Blackband, S. J. (2001). Nuclear magnetic resonance spectroscopy and imaging in animal research. IL AR Journal, 42(3), 189-208. https://doi.org/10.1093/ilar.42.3.189.

Cooper, G. M. (2000). The Central Role of Enzymes as Biological Catalysts. In G. M. Cooper (Ed.), The Cell: $A$ Molecular Approach. (2nd ed.) Sunderland (MA): Sinauer Associates. Retrieved from https://www.ncbi. nlm.nih.gov/books/NBK9921/

Cressey, D., \& Callaway, E. (2017). Cryo-electron microscopy wins chemistry Nobel. Nature News, 550(7675), 167. https://doi.org/10.1038/nature.2017.22738

Eduard Buchner-Facts. (2018). Retrieved from https://www.nobelprize.org/nobel_prizes/chemistry/laureates/1907/buchner-facts.html

Guan, L.-J., Ohtsuka, J., Okai, M., Miyakawa, T., Mase, T., Zhi, Y., ... Tanokura, M. (2015). A new target region for changing the substrate specificity of amine transaminases. Scientific Reports, 5, 10753. https://doi. org/10.1038/srep10753

Hospital, A., Goñi, J.R., Orozco, M., \& Gelpi, J.L. (2015). Molecular dynamics simulations: Advances and applications. Advances and Applications in Bioinformatics and Chemistry, 8, 37-47.https://doi.org/10.2147/AABC.S70333

Hutter, H. (2012). Fluorescent protein methods: Strategies and applications. Methods in Cell Biology, 107, 67-92. https://doi.org/10.1016/B978-0-12-394620-1.00003-5 
Jimenez-Rosales A., \& Flores-Merino M. V. (2018). Tailoring Proteins to Re-Evolve Nature: A Short Review. Molecular Biotechnology, 60(12), 946-974. https://doi.org/10.1007/s12033-018-0122-3.

Kjaergaard, M., \& Kragelund, B. B. (2017). Functions of intrinsic disorder in transmembrane proteins. Cellular and Molecular Life Sciences, 74(17), 3205-3224. https://doi.org/10.1007/s00018-017-2562-5

Lokko, Y., Heijde, M., Schebesta, K., Scholtès, P., Van Montagu, M., \& Giacca, M. (2018). Biotechnology and the bioeconomy-Towards inclusive and sustainable industrial development. New Biotechnology, 40, 5-10. https://doi.org/10.1016/j.nbt.2017.06.005

Mallela, S. P. S., Havale, S. H., Boddepalli, N. R., Gunji, N., Mokkapati, B. S., \& Limited, S. L. (2013). A novel process for the preparation of sitagliptin. Retrieved from https://www.google.com/patents/ WO2013114173A1?cl=en

Manas, L. (2016). Winner 2016. TAF. Retrieved from http://taf.fi/millennium-technology-prize/winner-2016/

Milczek, E. M. (2018). Commercial applications for enzyme-mediated protein conjugation: New developments in enzymatic processes to deliver functionalized proteins on the commercial scale. Chemical Reviews, 118(1), 119-141. https://doi.org/10.1021/acs.chemrev.6b00832

NAS (National Academy of Sciences). (2017). Raymond and Beverly Sackler. Prize in Convergence Research. Retrieved from http://www.nasonline.org/programs/awards/2017/Arnold.html

Packer, M. S., \& Liu, D. R. (2015). Methods for the directed evolution of proteins. Nature Reviews Genetics, 16(7), 379. https://doi.org/10.1038/nrg3927

Patel, A. K., Singhania, R. R., \& Pandey, A. (2017). Chapter 2-Production, purification, and application of microbial enzymes. In G. Brahmachari (Ed.), Biotechnology of Microbial Enzymes (pp. 13-41). https://doi. org/10.1016/B978-0-12-803725-6.00002-9

Pellis, A., Haernvall, K., Pichler, C. M., Ghazaryan, G., Breinbauer, R., \& Guebitz, G. M. (2016). Enzymatic hydrolysis of poly(ethylene furanoate). Journal of Biotechnology, 235, 47-53. https://doi.org/10.1016/j. jbiotec.2016.02.006

Peterson, M. E., Daniel, R. M., Danson, M. J., \& Eisenthal, R. (2007). The dependence of enzyme activity on temperature: Determination and validation of parameters. The Biochemical Journal, 402(2), 331-337. https://doi.org/10.1042/BJ20061143

Poluri, K. M., \& Gulati, K. (2017). Protein Engineering Techniques: Gateways to Synthetic Protein Universe. Springer Singapore. Retrieved from https://www.springer.com/gp/book/9789811027314

Ramírez, C. L., Martí, M. A., \& Roitberg, A. E. (2016). Steered molecular dynamics methods applied to enzyme mechanism and energetics. Methods in Enzymology, 578, 123-143. https://doi.org/10.1016/ bs.mie.2016.05.029.

RCSB PDB (2018). Homepage. Retrieved from https://www.rcsb.org/

Rigoldi, F., Donini, S., Redaelli, A., Parisini, E., \& Gautieri, A. (2018). Review: Engineering of thermostable enzymes for industrial applications. APL Bioengineering, 2(1), 011501. https://doi.org/10.1063/1.4997367

Roger Y. Tsien-Facts. (2018). Retrieved from https://www.nobelprize.org/prizes/chemistry/2008/ tsien/facts/

Rosenman, D. J., Huang, Y., Xia, K., Fraser, K., Jones, V. E., Lamberson, C. M., ... Bystroff, C. (2014). Green-lighting green fluorescent protein: Faster and more efficient folding by eliminating a cis-trans peptide isomerization event. Protein Science: A Publication of the Protein Society, 23(4), 400-410. https://doi.org/10.1002/ pro. 2421

Safran, R. J., \& Nosil, P. (2012). Speciation: The Origin of New Species. Nature Education Knowledge, 3(10), 17. 
Shi, Y. (2014). A glimpse of structural biology through X-ray crystallography. Cell, 159(5), 995-1014. https:// doi.org/10.1016/j.cell.2014.10.051

Singh, R., Kumar, M., Mittal, A., \& Mehta, P. K. (2016). Microbial enzymes: Industrial progress in 21 st century. 3 Biotech, 6(2). https://doi.org/10.1007/s13205-016-0485-8

The Nobel Prize in Chemistry 2013. (2018, June 15). Nobelprize.org. Retrieved from https://www.nobelprize. org/nobel_prizes/chemistry/laureates/2013/

The Nobel Prize in Chemistry 2018. (2018, October 10). NobelPrize.org. Retrieved from https://www.nobelprize.org/prizes/chemistry/2018/summary/

Thomson, S. C., \& Vallon, V. (2018). Renal effects of incretin-based diabetes therapies: Pre-clinical predictions and clinical trial outcomes. Current Diabetes Reports, 18(5), 28. https://doi.org/10.1007/s1 1892-018-0991-7

Tiwari, V. (2016). In vitro engineering of novel bioactivity in the natural enzymes. Frontiers in Chemistry, 4(39). https://doi.org/10.3389/fchem.2016.00039

Tsien, R. Y. (1998). The green fluorescent protein. Annual Review of Biochemistry, 67(1), 509-544. https://doi. org/10.1146/annurev.biochem.67.1.509

Urbanek, A. K., Rymowicz, W., Strzelecki, M. C., Kociuba, W., Franczak, Ł., \& Mirończuk, A. M. (2017). Isolation and characterization of arctic microorganisms decomposing bioplastics. AMB Express, 7(1), 148. https://doi.org/10.1186/s13568-017-0448-4

US EPA, O. (2013a, March 8). Presidential Green Chemistry Challenge: 2006 Greener Synthetic Pathways Award [Overviews and Factsheets]. Retrieved from https://www.epa.gov/greenchemistry/presidential-green-chemistry-challenge-2006-greener-synthetic-pathways-award

US EPA, O. (2013b, March 12). Presidential Green Chemistry Challenge: 2010 Greener Reaction Conditions Award [Overviews and Factsheets]. Retrieved from https://www.epa.gov/greenchemistry/presidential-green-chemistry-challenge-2010-greener-reaction-conditions-award

Valavanidis, A. (2017). Biocatalysis and directed evolution in the pharmaceutical industry. New developments for 'green' synthetic methods of high value pharmaceuticals. Pharmakeftiki, 15.

Wang, H.-W., \& Wang, J.-W. (2016). How cryo-electron microscopy and X-ray crystallography complement each other. Protein Science, 26(1), 32-39. https://doi.org/10.1002/pro.3022

Wójcikowski, M., Ballester, P. J., \& Siedlecki, P. (2017). Performance of machine-learning scoring functions in structure-based virtual screening. Scientific Reports, 7, 46710. https://doi.org/10.1038/srep46710

Yang, J., Ruff, A. J., Arlt, M., \& Schwaneberg, U. (2017). Casting epPCR (cepPCR): A simple random mutagenesis method to generate high quality mutant libraries. Biotechnology and Bioengineering, 114(9), 1921-1927. https://doi.org/10.1002/bit.26327

Yu, Z., Chen, L., Park, Y., Cong, Q., Han, X., Zhao, B., \& Jung, Y. M. (2016). The mechanism of an enzymatic reaction-induced SERS transformation for the study of enzyme-molecule interfacial interactions. Physical Chemistry Chemical Physics, 18(46), 31787-31795. https://doi.org/10.1039/C6CP05978C

\section{BY-NC-ND}

